\title{
Geoturismo na área de abrangência do COREDE Campanha ('metade sul' do Rio Grande do Sul, Brasil), parte II: elementos geopatrimoniais ex situ, contextos e identidades
}

\author{
Geoturismo em el area del COREDE Campanha (mitad sur \\ del Estado de Rio Grande do Sul, Brasil), parte II: elementos \\ geopatrimoniales ex situ, contextos e identidades
}

\section{Geotourism in the territory of the COREDE Campanha ('southern-half' of the Rio Grande do Sul State, Brazil): ex situ geoheritage elements, contexts and identities}

André Weissheimer de Borba awborba.geo@gmail.com Universidade Federal de Santa Maria, UFSM, Santa Maria, RS

Felipe Guadagnin felipe.guada@yahoo.com.br Universidade Federal do Pampa, Unipampa, Caçapava do Sul, RS

Vinícius Matté vinimatte@msn.com Universidade Federal do Pampa, Unipampa, Caçapava do Sul, RS

Felipe Caron pati0403@gmail.com Universidade Federal do Rio Grande do Sul, UFRGS, Campus Litoral Norte, Tramandai, RS

Patrícia Freitas Ferreira pati0403@gmail.com Universidade Federal do Pampa, Unipampa, Caçapava do Sul, RS

Sissa Kumaira sissakumaira@gmail.com Universidade Federal do Pampa, Unipampa, Caçapava do Sul, RS

Renato Pereira Lopes paleonto_furg@yahoo.com.br Universidade Federal de Santa Catarina, UFSC, Florianópolis, SC Jaciele Carine Sell jacics@gmail.com Universidade Federal de SantaMaria, UFSM, Santa Maria, RS 
Simone Marafiga Degrandi

simonemdgeo@gmail.com

Universidade Federal de Santa Maria, UFSM, Santa Maria, RS

Ana Paula Souza Corrêa

anacorrea.cp@gmail.com

Universidade Federal do Pampa, Unipampa, Caçapava do Sul, RS

Elisângela Lopes da Silva

silva.elislopes@gmail.com

Universidade Federal de Santa Maria, UFSM, Santa Maria, RS

Luiz Paulo Martins e Souza

martinsesouza@gmail.com

Universidade Federal de Santa Maria, UFSM, Santa Maria, RS

Camile Urban

camile.urban@gmail.com

Universidade Federal de Pelotas, UFPel, Pelotas, RS

Adriano Luis Heck Simon

adrianosimon@gmail.com

Universidade Federal de Pelotas, UFPel, Pelotas, RS

Eliseu Balduíno

vicent.lyh@gmail.com

Universidade Federal de Santa Maria, UFSM, Santa Maria, RS

Dílson Vargas-Peixoto

Iiuni_Kantal@hotmail.com

Universidade Federal de Santa Maria, UFSM, Santa Maria, RS

Resumo: Este trabalho apresenta um levantamento de elementos geopatrimoniais ex situ, além de contextos e identidades vinculadas à geodiversidade, para a área de abrangência do COREDE Campanha, na 'metade sul' gaúcha. Os elementos ex situ destacados são fósseis de animais extintos do Permiano (anfíbios e pararrépteis) e do Pleistoceno (megafauna, especialmente as preguiças-gigantes). Os contextos geológicos curiosos ou interessantes ao público do geoturismo são os pântanos formadores de carvões, uma lasca de litosfera oceânica e áreas cratônicas muito antigas. Por fim, a identidade garimpeira e a memória da mineração de metais, juntamente com seu rico patrimônio cultural, também constituem atrativos turísticos que, interpretados de forma interessante, podem se somar aos geomonumentos de destaque, no âmbito de uma estratégia de geoturismo no COREDE Campanha.

Palavras-chave: geodiversidade, geopatrimônio, geomemória, interpretação;

Resumen: Este trabajo trae un relevamiento de elementos ex situ del patrimonio geológico, además de contextos e identidades vinculadas a la geodiversidad, para el territorio del COREDE Campanha, en la 'mitad sur' del Estado de Rio Grande do Sul, Brasil. Los elementos ex situ destacados son los fósiles de animales extintos del Permiano (anfibios y para-reptiles) y del Pleistoceno (megafauna, sobre todo los perezosos terrestres). Los contextos geopatrimoniales curiosos o interesantes son 
los charcos formadores del carbón mineral, una lasca de litosfera oceánica y áreas pertenecientes a un cratón muy antiguo. Finalmente, la identidad y la memoria de la minería de metales, con su rico patrimonio construido, son también atractivos turísticos que, con una adecuada interpretación, pueden sumarse a los lugares geológicos, en el seno de una estrategia de geoturismo para el COREDE Campanha.

Palabras-clave: geodiversidad, geopatrimonio, geomemoria, interpretación;

\begin{abstract}
This paper brings an assessment of ex situ geoheritage elements, as well as of geodiversity-related contexts and identities for the COREDE Campanha territory of the 'southern half' of Rio Grande do Sul State, Brazil. The ex-situ elements are fossils of extinct animals of Permian (amphibians and para-reptiles) and Pleistocene (mammal megafauna, especially ground sloths) ages. Curious or interesting geoheritage contexts, such as the coal-forming Permian wetlands, an oceanic lithosphere slab, or very ancient craton areas have also been highlighted. Finally, the paper approaches the artisanal gold miners' identity and the metallic ore mining memory, along with their rich built cultural heritage. By means of an adequate interpretation, such features can be added to geosites within a broad geotourism strategy for the territory of COREDE Campanha.
\end{abstract}

Keywords: geodiversity, geoheritage, geomemory, interpretation;

\title{
INTRODUÇÃO
}

O geopatrimônio de um determinado território ou área de estudo compõe-se, em primeiro lugar, de locais geológicos de interesse, também chamados de geossítios ou geomonumentos (BRILHA, 2016; BORBA; SELL, 2018), os quais possuem certamente expressiva atratividade turística. A área de abrangência do COREDE Campanha, formada pelos municípios de Aceguá, Bagé, Caçapava do Sul, Candiota, Dom Pedrito, Hulha Negra e Lavras do Sul, em uma extensão de mais de 18 mil $\mathrm{Km}^{2}$, possui pelo menos oito grandes áreas complexas passiveis de um expressivo desenvolvimento geoturístico. São elas: (1) o alto de Caçapava do Sul; (2) a Serra de Santa Bárbara; (3) a Serra do Segredo; (4) as Pedras das Guaritas; (5) a área de Lagoa da Meia-Lua/Palma; (6) o Rincão do Inferno; (7) a Casa de Pedra ou Pico do Morcego; e (8) o platô do Taquarembó (BORBA et al., parte I, neste número).

Entretanto, uma série de outros elementos materiais e imateriais relacionados à geodiversidade podem também ser considerados como pertencentes ao geopatrimônio, e valorizados na idealização de uma estratégia de geoturismo. Elementos geopatrimoniais ex situ, já retirados de seus locais originais de ocorrência, como fósseis e suas reconstituições (morfológicas e ambientais), possuem também uma 'geomemória' que merece divulgação. Contextos geológicos relevantes para o meio acadêmico ou curiosos para o público leigo também podem ser explorados, mesmo não constituindo áreas de grande complexidade ou destaque na paisagem. Isso também é válido para identidades singulares relacionadas a elementos da geodiversidade, como é o caso da identidade mineira (relacionada à mineração) e garimpeira, por exemplo.

O objetivo deste trabalho é caracterizar e avaliar os elementos materiais e imateriais que, mesmo não estando representados nos oito geomonumentos mais atrativos do 
COREDE Campanha, merecem ser valorizados e divulgados. Da mesma forma, pretende-se sugerir iniciativas de geoturismo e interpretação geopatrimonial para esses elementos, com vistas ao desenvolvimento de estratégias mais integradas, em âmbito de COREDE, que sejam reconhecidas e validadas por todos os municípios integrantes do Conselho. $\mathrm{O}$ presente trabalho complementa o artigo de Borba et al., parte I, neste mesmo número da Terr@ Plural, direcionado aos geomonumentos.

\section{Geoturismo baseado em elementos $e x$ situ, contextos e identidades}

Conforme explicitado anteriormente (BORBA et al., parte I, neste número), este trabalho entende geoturismo como o turismo sustentável, respeitoso com a cultura e o meio ambiente locais, onde os principais atrativos sejam elementos materiais ou imateriais, in situ ou ex situ, da geodiversidade e/ ou do geopatrimônio. Com isso, busca oferecer uma 'viagem no tempo', através da interpretação, e se aproximar ao máximo de um turismo de base comunitária, revertendo os resultados econômicos de sua implementação para a comunidade, trazendo bem-estar a toda a coletividade (BORBA; SELL, 2018). Elementos da geodiversidade $e x$ situ, sobretudo fósseis, além de contextos e identidades relacionados à natureza abiótica, também podem ser incluídos nessas estratégias.

O geopatrimônio de cunho paleontológico, representado pelos fósseis, suas assembleias e interpretações paleoambientais, constitui um conjunto de materiais geológicos de substancial atratividade turística. Uma série de fatores, entretanto, dificulta o aproveitamento turístico dos fósseis in situ: (a) a necessidade de estudos de laboratório para sua identificação e classificação precisa; (b) os tratamentos físico-químicos aos quais os fósseis devem ser submetidos para sua preservação; (c) a dificuldade de preservação de fósseis nos sítios paleontológicos frente aos agentes do intemperismo; e (d) as restrições e dificuldades de acesso a muitos locais de afloramento de fósseis. Por isso, o geoturismo paleontológico é, sobretudo, realizado pela visitação de elementos ex situ, ou seja, de materiais que já foram retirados de seu local original de afloramento. Diversos territórios onde o geoturismo é um importante motor de desenvolvimento encontram nos fósseis seu principal trunfo, como é o caso da comarca espanhola de Maestrazgo, na província de Teruel (Aragón, Espanha). Naquele território, conhecido turisticamente como Territorio Dinópolis (ALCALÁ-MARTÍNEZ, 2011), os dinossauros são os protagonistas. Enquanto o edifício-sede do território é um misto de museu, centro interpretativo e parque temático, outros sete modernos centros interpretativos ('centros satélites'), de dimensões menores, acham-se distribuídos em localidades pequenas e menos povoadas, com exposições de fósseis reais, réplicas e reconstituições em tamanho real. Por fim, a cidade de Galve conta com um parque temático ao ar livre com reconstituições paleoartísticas de dinossauros. Para se avaliar a importância do turismo paleontológico naquele território, desde a inauguração em 2004, até o ano de 2013, foram vendidos 69.465 ingressos apenas para o 'centro satélite' de Dinópolis em Galve, uma localidade com apenas 168 habitantes fixos (FERNÁNDEZ-MARTÍNEZ et al., 2014). 
Contextos geológicos mais amplos, de relevância científica, social ou cultural, mesmo desprovidos de geomonumentos destacados, podem também ser objeto do planejamento de programas de geoturismo. Nita e Myga-Piatek (2014), por exemplo, analisam o potencial geoturístico de antigas áreas de mineração (post-mining areas) de carvão na Polônia, apontando cavas a céu aberto e até mesmo locais de lançamento de rejeitos de carvão como tendo tal potencial. Enquanto isso, em um contexto semelhante, em áreas de afloramento de camadas de carvão ao sul do País de Gales, o South Wales Coalfield conta com trilhas geoturísticas, painéis interpretativos, folhetos, resgate de imagens e equipamentos históricos, aplicativo de celular e um 'jardim carbonífero', onde plantas fósseis registradas nas camadas de carvão podem ser comparadas a samambaias atuais, em um ambiente lúdico e de aprendizado (EVANS; CLEAL; THOMAS, 2018). Os contextos geológicos de áreas cratônicas muito antigas também estão sendo vistos como potencial atrativo geoturístico, mesmo que seus afloramentos não possuam, em geral, substancial destaque na paisagem ou visibilidade. Na Austrália Ocidental, o contexto do cráton Pilbara, com suas rochas granito-greenstone e seus estromatólitos do Arqueano, está sendo trabalhado no sentido de uma trilha pedestre chamada Dawn of Life (Aurora da Vida), com cerca de 1.000 metros de extensão (GREY; CLARKE; HICKMAN, 2012).

Por fim, diversas identidades foram sendo construídas, ao longo do tempo, a partir do uso dos elementos da geodiversidade. O movimento do tropeirismo, por exemplo, entre o Rio Grande do Sul e as Minas Gerais, a partir do século XVI até o início do século XIX, utilizou para seu deslocamento o corredor dos Campos Gerais, sobre rochas sedimentares. Uma Rota dos Tropeiros já avaliada do ponto de vista do geoturismo (PIEKARZ; LICCARDO, 2007), projetada de forma a integrar aspectos históricos, culturais e geológico-geomorfológicos. Outra presença forte em programas geoturísticos, principalmente nos domínios da Chapada Diamantina, na Bahia, é a da identidade garimpeira. O projeto de geoparque Serra do Sincorá, entre Lençóis e Mucugê (BA), prevê visitas a estruturas antigas de lavra garimpeira, a depósitos sedimentares produzidos por essas atividades extrativas e, também, ao atrativo cultural 'Rancho Garimpeiro', onde pessoas que exerceram essa atividade podem conversar com o público e simular a busca e a identificação de um diamante (NOLASCO et al., 2017).

\section{METODOLOGIA}

Para este trabalho a revisão bibliográfica foi a etapa metodológica permanente e mais importante. Além de toda a bibliografia citada no item anterior, trabalhos voltados ao COREDE Campanha relacionados a fósseis (ARAÚJO, 1985a, 1985b; OLIVEIRA; DUTRA; ZELTZER, 2002; DIAS; BARBERENA, 2001; CISNEROS; ABDALA; MALABARBA, 2005), a contextos geológicos singulares (HARTMANN, 1991; HARTMANN; REMUS, 2000; HOLZ; CARLUCCI, 2000; JASPER et al., 2009) e à identidade garimpeira (CARVALHO, 2013) receberam atenção especial. Foram consultados sítios eletrônicos da internet, de entidades públicas ou privadas, relacionados aos sete municípios do COREDE Campanha, no sentido de identificar usos turísticos, recreativos ou simbólicos desses elementos da 
geodiversidade. Após o que foram realizadas saídas a campo, visitas a museus e acervos, no sentido de avaliar qualitativamente e registrar fotograficamente esses elementos, inclusive utilizando um drone.

\section{RESULTADOS E DISCUSSÃO}

\section{Elementos geopatrimoniais ex situ - fósseis do COREDE Campanha}

As áreas planas a levemente onduladas da porção sul do COREDE Campanha, sem qualquer geomonumento relevante em termos de destaque na paisagem, guardam elementos com forte potencial de atratividade turística: os fósseis de pararrépteis e anfíbios do Permiano. As porções meridionais dos municípios de Bagé e Dom Pedrito, bem como a totalidade dos territórios dos municípios de Aceguá, Candiota e Hulha Negra, têm como substrato geológico camadas sedimentares de pouca resistência ao intemperismo físico e químico. São camadas de arenitos, siltitos, argilitos e sedimentos carbonosos, que registram um período no qual a região formava uma ampla depressão, ocupada por sistemas que variaram entre o glacial, o costeiro, o marinho raso e o marinho profundo, até a nova continentalização. Em termos da estratigrafia formal, essas rochas pertencem, da base para o topo, às unidades Itararé, Rio Bonito, Palermo, Irati, Serra Alta, Teresina e Rio do Rasto, todas do Período Permiano (290 a $250 \mathrm{Ma}$ ) e com ampla distribuição no centro-sul do Brasil, na chamada Bacia do Paraná (HOLZ; CARLUCCI, 2000; MENESES, 2000).

Na unidade mais jovem desse intervalo estratigráfico, Rio do Rasto (entre 260 e 250 Ma), ocorrem conteúdos fossilíferos interessantes na área de abrangência do COREDE Campanha. No Km 176 da rodovia federal BR-153, entre Bagé e Aceguá, foi encontrada a porção média da mandíbula inferior, com comprimento preservado de $32 \mathrm{~cm}$, de um anfíbio de focinho longo, da ordem dos temnospôndilos (Temnospondyli). O novo táxon recebeu o nome científico de Bageherpeton longignathus (DIAS; BARBERENA, 2001), como uma referência à sua região de descoberta. As características do fóssil encontrado sugerem que esse anfíbio (Fig. 1A) tinha uma dieta piscívora, que usaria suas mandíbulas para imobilizar e esmagar suas presas durante o fechamento da boca (DIAS; BARBERENA, 2001).

Também na BR-153, cerca de 58 quilômetros ao sul da cidade de Bagé, no ano de 1979 foram localizados fósseis de coloração cinza-escura, vinculada à presença de óxidos de manganês (ARAÚJO-BARBERENA, 1990). Tais fósseis, incluindo crânios, esqueleto axial, pélvis e parte dos membros, foram atribuídos a três indivíduos de um pararréptil herbívoro da família dos pareiasaurídeos (Pareiasauridae), animais grandes, pesados e fortemente encouraçados, de crânio pequeno e ornamentado (Fig. 1B), que podem estar relacionados às atuais tartarugas, o Provelosaurus americanus (LEE, 1997).

Sugere-se, em nome de uma divulgação científica com possíveis implicações geoturísticas, que réplicas ou reconstituições sejam disponibilizadas ao público em linguagem acessível e vinculando a seres vivos modernos (por exemplo, uma reconstituição de um Provelosaurus em um pequeno lago com tartarugas vivas). 
Figura 1 - Reconstituição paleoartística dos animais permianos cujos fósseis foram encontrados em afloramentos da unidade Rio do Rastro, ao longo da rodovia federal BR-153, entre Bagé e Aceguá, no COREDE Campanha: (A) Bageherpeton longignathus; e (B) Provelosaurus americanus.
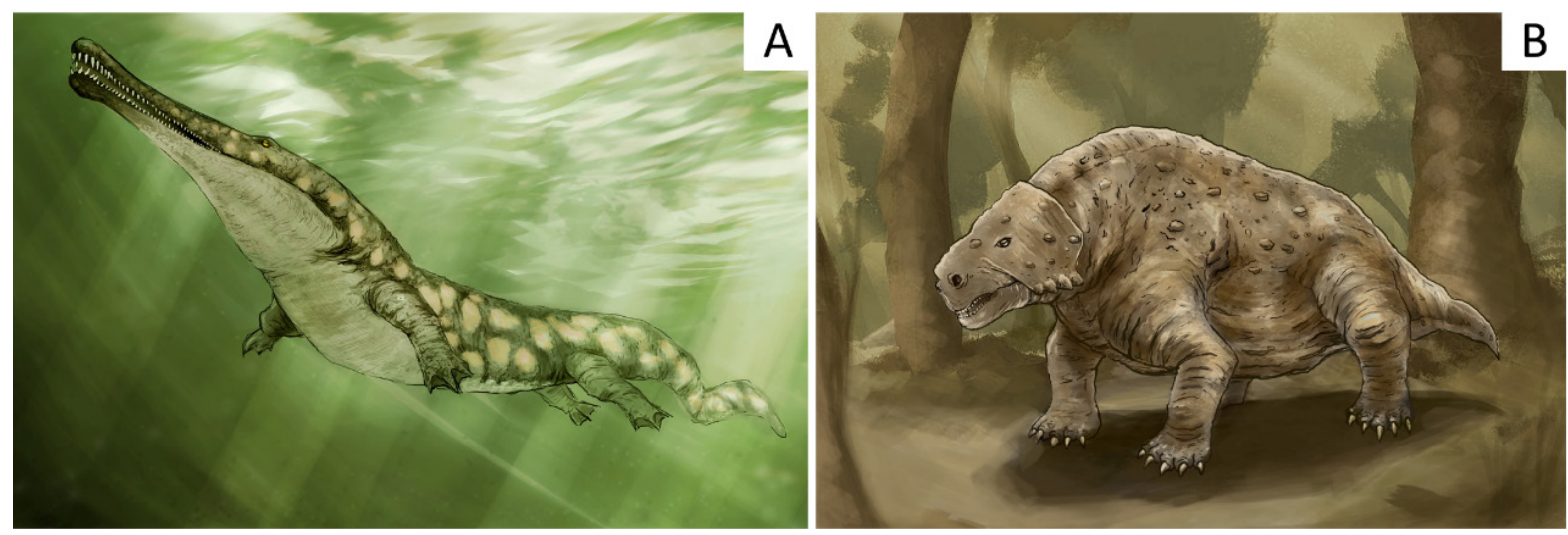

Fonte: ilustrações de Vicent Solar.

Um tema de ainda maior atratividade turística, na área de abrangência do COREDE Campanha, é a presença de fósseis da megafauna do Pleistoceno, especialmente as preguiças-terrícolas ou preguiças-gigantes. Esses animais, extintos há cerca de 11 mil anos na transição para o Holoceno (MANZIG; WEINSCHÜTZ, 2012), despertam grande curiosidade não apenas por suas dimensões - as preguiças-gigantes podiam chegar a 6 metros de comprimento - mas também pelo fato de terem convivido com os primeiros humanos das Américas e por terem sido representados nos filmes de animação A Era do Gelo.

O termo megafauna refere-se a animais de diversos grupos faunísticos que alcançaram grande porte, sobretudo no Pleistoceno. O isolamento da América do Sul em relação a outros continentes ao longo do Cenozoico (REGUERO et al., 2014; CHÁVEZ-HOFFMEISTER, 2016) favoreceu a evolução de animais bastante singulares, entre eles os Xenarthra (tamanduás, preguiças e tatus). Dentre os Xenarthra, o grupo dos Folivora, que reúne todos os diferentes tipos de preguiças evoluiu desde espécies pequenas, escaladoras de árvores e bem adaptadas a florestas, até chegar às preguiças-gigantes ou preguiças-terrícolas, adaptadas a ambientes mais abertos e à locomoção quadrúpede (e eventualmente bípede).

Em Caçapava do Sul, os mais destacados fósseis da megafauna do Pleistoceno são de três gêneros de preguiças-terrícolas: dois representantes da família Megatheriidae, das maiores preguiças-gigantes (4-6 metros de comprimento), representadas pelos gêneros Megatherium e Eremotherium; e um representante da família Mylodontidae, do gênero Lestodon, que chegava a 3 metros de comprimento (OLIVEIRA; DUTRA; ZELTZER, 2002; VARGAS-PEIXOTO; DA-ROSA; KERBER, 2017). Estes fósseis foram encontrados no arroio Pessegueiro (no 'passo do megatério'), no arroio Seival e num afluente do arroio Carajá.

A presença de ambos os Megatheriidae no registro fossilífero caçapavano demonstra que a região constituía, já no final do Pleistoceno, uma zona de transição entre os ambientes de parque, aos quais o Eremotherium era adaptado, e ambientes abertos pampeanos, habitats preferenciais do gênero Megatherium (GALLO et al., 2013). As flutuações climáticas modificavam o ambiente de forma cíclica: em períodos glaciais, a região ficava mais seca e fria, permitindo o avanço dos campos e o predomínio do Megatherium; em períodos 
quentes, interglaciais, elementos florestais e espécies de clima mais quente e úmido se tornavam predominantes, propiciando a chegada de Eremotherium. Essas duas espécies eram herbívoras comedoras de brotos (browsers). Já as preguiças do gênero Lestodon eram animais herbívoros pastadores (grazers), bem adaptados aos mosaicos campo-floresta distribuídos pelo pampa e pelos biomas vizinhos do Chaco e Mata Atlântica. Lestodon seria o único com o hábito de cavar tocas, e possivelmente é um dos responsáveis pelas paleotocas encontradas em diversas partes do Rio Grande do Sul.

Por seu grande potencial na educação e na atratividade turística, as preguiças-gigantes têm alcançado um significativo protagonismo nas estratégias de geoconservação em Caçapava do Sul. Como resultado do projeto financiador do presente trabalho, uma reconstituição do Megatherium em tamanho real produzida em ferro, poliuretano e resina, foi instalada no acesso ao campus de Caçapava do Sul da UNIPAMPA (Fig. 2C). Também uma cervejaria artesanal local produziu uma edição especial de um de seus estilos de cerveja com um rótulo temático, com uma representação artística da preguiça-gigante no rótulo e um texto explicativo sobre esses representantes da megafauna do Pleistoceno (Fig. 2D), além da inscrição Caçapava do Sul, capital gaúcha da geodiversidade, fatores que a tornam um dos primeiros 'geoprodutos' do sul do país (RODRIGUES; CARVALHO; JACINTO, 2017).

Figura 2 - Registros fossilíferos e evidências do recente protagonismo das preguiças-gigantes (Folivora) em Caçapava do Sul, no território do COREDE Campanha: (A) tíbia e fêmur de Lestodon no leito de um arroio; (B) garra fóssil de Lestodon; (C) reconstituição paleoartística de um Megatherium americanum posicionada no acesso ao campus Caçapava do Sul da UNIPAMPA; (D) cerveja artesanal com rótulo temático da preguiça-gigante.

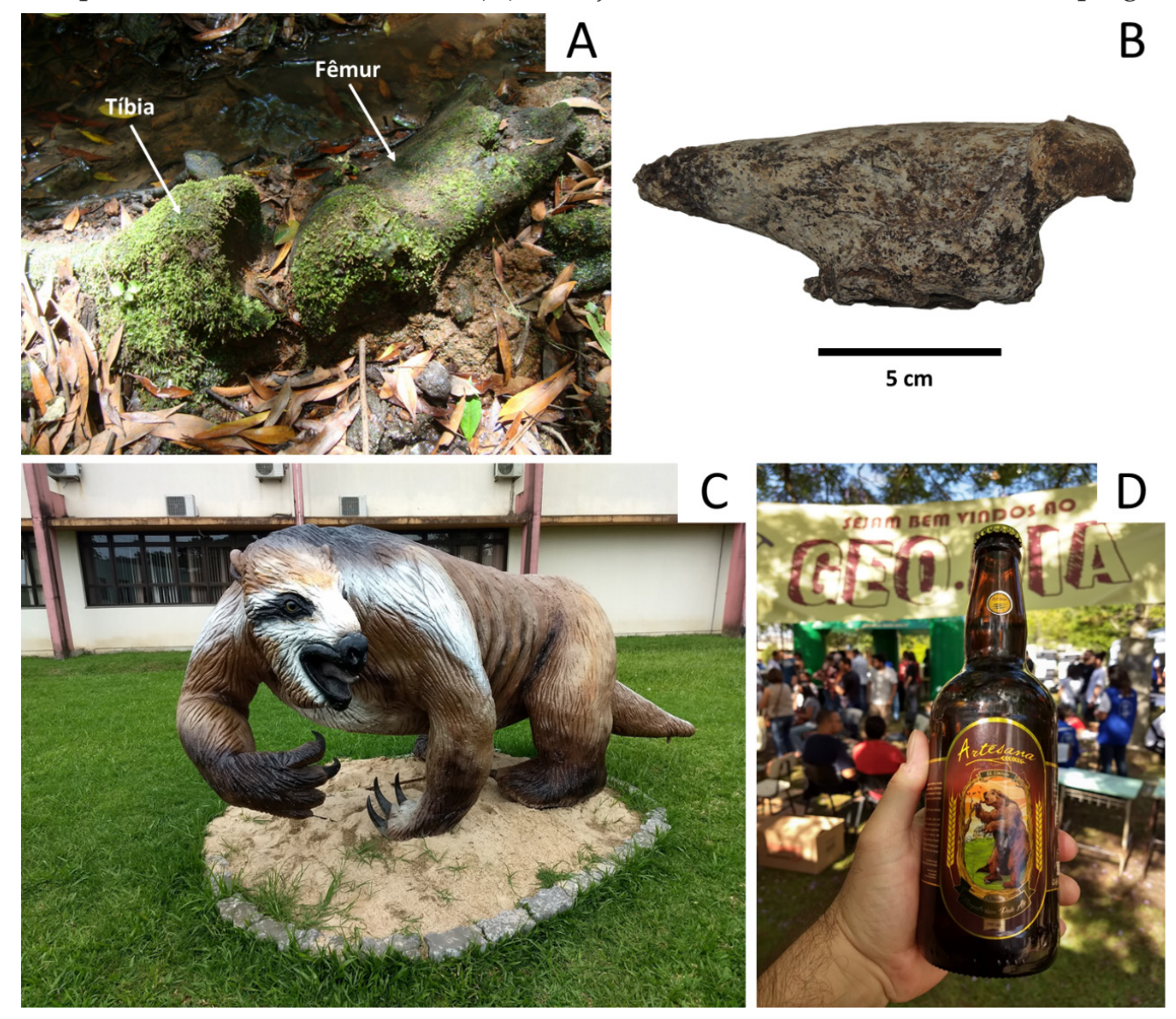

Fontes: fotos obtidas pelos autores. 


\section{Contextos e identidades}

A porção leste do município de Dom Pedrito, ao longo da BR-293 em direção a Bagé, está assentada sobre uma geodiversidade muito interessante. Afloram ali, em coxilhas, lajeados de arroios ou pequenos morrotes, rochas extremamente antigas, do final do Arqueano e início do Paleoproterozoico, entre 2,55 e 2,02 bilhões de anos atrás. Essa área corresponde ao Complexo Granulítico Santa Maria Chico (HARTMANN, 1991), unidade composta por granulitos básicos, máficos, com granada, e granulitos trondjemíticos, ácidos, ambos intercalados a gnaisses diversos, formações ferríferas e rochas ultramáficas como piroxenitos e lherzolitos (HARTMANN; REMUS, 2000; CHEMALE JUNIOR, 2000). Essas correspondem a litologias juvenis, derivadas diretamente do manto terrestre, há cerca de 2,55 Ga, em um ambiente de arco de ilhas do final do Arqueano, e metamorfizadas já no Paleoproterozoico, entre 2,10 e 2,02 Ga, em um evento de colisão continental (HARTMANN; REMUS, 2000; CHEMALE JUNIOR, 2000). Segundo os autores citados, esse evento metamórfico do início do Paleoproterozoico teria ocorrido na base de uma crosta espessa (30 km de espessura), em condições de até $10 \mathrm{~kb}$ de pressão e $850^{\circ} \mathrm{C}$ de temperatura. Esse seria o registro (aflorante) de crosta continental mais profunda e desenvolvida sob as condições metamórficas mais extremas já identificadas no Brasil (HARTMANN; REMUS, 2000). Portanto a informação importante, com potencial de ser levada ao público do geoturismo, é a de que as nascentes do arroio Santa Maria Chico fazem parte de uma área de borda de uma das massas continentais mais antigas do planeta, o cráton La Plata. Além disso, seria importante popularizar que tal massa continental teria formado, juntamente com outros blocos continentais sul-americanos e africanos amalgamados há 2 bilhões de anos, o primeiro 'supercontinente' da Terra, chamado de 'Atlântica' (HARTMANN, 2002). Promover uma 'viagem no tempo' ao Arqueano ou ao Paleoproterozoico é complexo, mas interessante do ponto de vista filosófico. Significa transportar os visitantes a um tempo de continentes completamente desertos, desprovidos de qualquer sinal de vida macroscópica, sob uma atmosfera onde dominavam metano, amônia e CO2, e onde recém começava a surgir o oxigênio livre, que levaria às condições atuais.

Outro contexto geológico diferente e curioso do ponto de vista científico está na área centro-sul do município de Lavras do Sul, onde uma elevação de pouco destaque na paisagem guarda uma singularidade geológica, o substrato do chamado Cerro Mantiqueiras (Fig. 3 A). Trata-se de uma sucessão ofiolítica, ou seja, rochas pertencentes a uma lasca de litosfera oceânica de mais de $700 \mathrm{Ma}$, posteriormente metamorfizada e deformada. As rochas aflorantes hoje são harzburgitos, serpentinitos, xistos magnesianos e metabasaltos de fácies anfibolito, localmente com estruturas almofadadas, na maior sequência de rochas ultramáficas do sul do Brasil (HARTMANN; REMUS, 2000), cujo potencial geoturístico já havia sido levantado por Borba (2014). Interpretar a existência de um "oceano no meio do pampa" é também um grande desafio de adaptação da linguagem geológica (no caso, geotectônica), uma das essências do geoturismo. Cabe salientar que o Geoparque Mundial UNESCO Terras de Cavaleiros, no nordeste de Portugal, possui rochas ofiolíticas como um de seus principais atrativos (GONÇALVES, 2013), em um contexto de significativa justaposição de associações petrotectônicas distintas. A sucessão ofiolítica aflorante mais 
jovem, e também mais conhecida no meio geocientífico, o ofiolito de Troodos, na ilha de Chipre, também se encontra em um território hoje certificado como Geoparque Mundial UNESCO Troodos, com várias geo-trilhas sobre peridotitos e outros produtos da evolução dos ofiolitos (BUKALA; ZBOINSKA; SZADKOWSKI, 2016).

Figura 3 - Panorama do Cerro Mantiqueiras, no centro-sul do município de Lavras do Sul, cujo substrato é constituído por uma sucessão ofiolítica, representativa de "um oceano no meio do pampa".

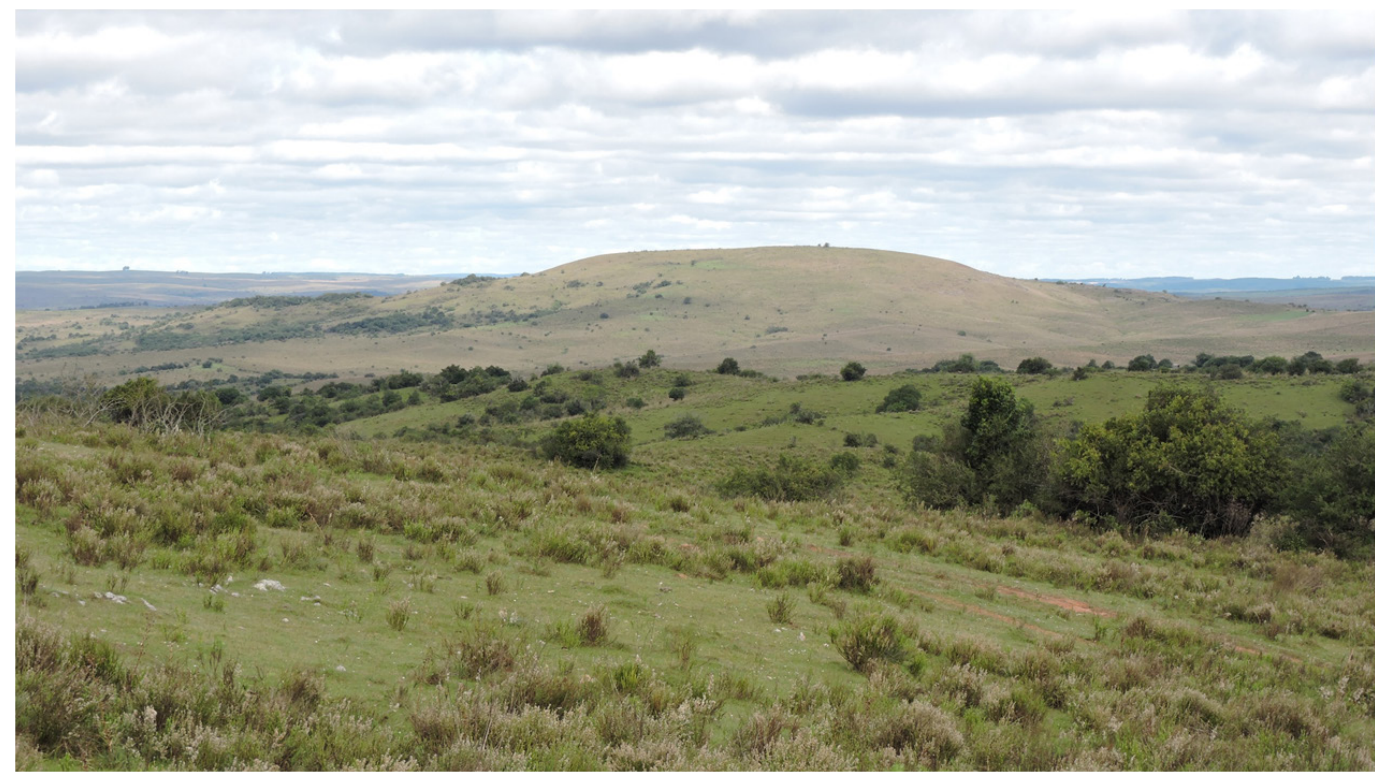

Fonte: foto obtida pelos autores.

Outro contexto geológico-estratigráfico de substancial potencial geoturístico são as camadas de carvão mineral da jazida Candiota, no município de mesmo nome, com algo em torno de 12 bilhões de toneladas totais dessa rocha em subsuperfície (SÜFFERT, 1997), compondo cerca de 38\% de todo o carvão brasileiro (ORLANDI FILHO; KREBS; GIFFONI, 2006), e ainda em fase de lavra ativa (Fig. 4A, 4B, 4C). O carvão mineral extraído em Candiota alimenta, sobretudo, as usinas termelétricas locais, que marcam a paisagem com suas características torres de resfriamento de água (Fig. 4D). Afloramentos das camadas de carvão não são comuns, pois a maior parte está em subsuperfície, mas há camadas tabulares e suavemente dobradas de siltitos carbonosos, de coloração cinza muito escura, associados a arenitos (Fig. 4E, 4F), ao longo da linha férrea que corta a porção norte do município, junto à rodovia BR-293.

Do ponto de vista do geoturismo, ainda mais importante que o destaque à exploração e uso econômico e energético dos carvões de Candiota são seus processos e paleoambientes de formação. Todas as unidades estratigráficas do início do Permiano no Rio Grande do Sul vinculam-se, segundo Holz e Carlucci (2000), a uma transição desde um ambiente periglacial e marinho raso (unidade Itararé), passando a um ambiente costeiro e lagunar (unidade Rio Bonito) e chegando à máxima inundação marinha (unidades Palermo e Irati). As associações de fácies que contêm carvões sugerem planícies de inundação fluviais, planícies distributárias de deltas e, no caso de camadas mais contínuas de carvão, turfeiras associadas a ambientes lagunares costeiros mais protegidos (HOLZ; CARLUCCI, 2000). 
É interessante também registrar, como parte da interpretação, que essa planície costeira recebia periodicamente deposições distais de cinzas vulcânicas, possivelmente de origem proto-Andina, registradas nas camadas chamadas de tonsteins (MATOS et al., 2000).

A paleoflora dos níveis de carvão, identificada por palinologia, bem como das camadas de rochas sedimentares clásticas correlatas, também indica um ambiente costeiro arenoso, lagunar, influenciado pelo mar, com baixa disponibilidade de nutrientes. Predominava um estrato arbóreo caracterizado por licófitas arborescentes (JASPER et al., 2009), sobretudo do gênero Brasilodendron: árvores altas, de cascas escamosas, ramificadas no topo, com um conjunto de raízes bem distribuídas horizontalmente (MANZIG; WEINSCHÜTZ, 2012). No sub-bosque cresciam coníferas, pteridospermas (samambaias com sementes), licófitas herbáceas e filicófitas. Frequentes incêndios nos arredores dos corpos lagunares deram origem a ocorrências de charcoal, um tipo de carvão vegetal associado aos fósseis (JASPER et al., 2009). Para o território do COREDE Campanha, especialmente em sua porção sul, seria interessante a implantação futura de um equipamento turístico-educativo, como um centro interpretativo, por exemplo, dedicado a toda a evolução no período Permiano - desde um clima frio, influenciado pelas glaciações no Supercontinente Gondwana, passando por um ambiente costeiro/pantanoso como o descrito acima, uma inundação marinha, e o retorno progressivo das condições continentais, dando origem aos anfíbios e para-répteis abordados acima.

Figura 4 - Aspectos do contexto geopatrimonial do carvão mineral em Candiota, porção sul do COREDE Campanha: (A) panorama geral da lavra atual de carvão da Jazida Candiota, com detalhes (B, C) da atividade extrativa; (D) vista aérea da Usina Termelétrica de Candiota; (E, F) camadas levemente dobradas de siltitos carbonosos e arenitos ao longo da linha férrea, junto à rodovia BR-293.
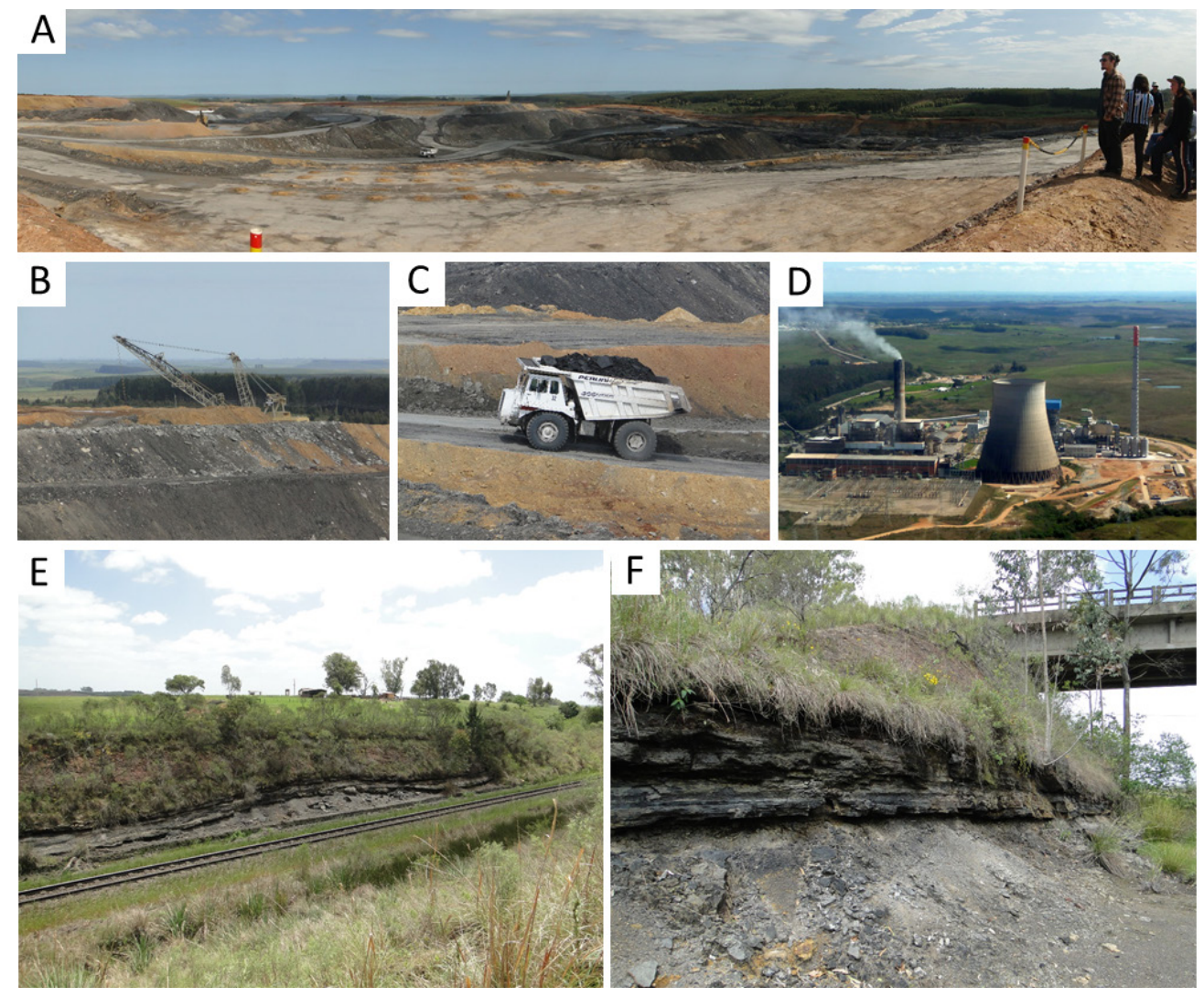

Fonte: fotos obtidas pelos autores. 
Outro conjunto de elementos materiais e imateriais a ser explorado, do ponto de vista do geoturismo, é a memória da mineração. Lavras do Sul possui a singularidade de constituir a única cidade do Rio Grande do Sul cuja origem está diretamente relacionada à mineração e ao garimpo do ouro, especificamente nos depósitos de cascalhos do rio Camaquã e do arroio Camaquã das Lavras. O inventário e a valorização das construções relacionadas a essa memória foram temas do trabalho de Carvalho (2013). A autora narra que a descoberta do ouro na localidade remonta ao final do século XVIII, explorado de 1796 a 1860 por garimpeiros de todas as regiões, e teria se dado, segundo o imaginário local, através da descoberta de uma pepita de ouro com a forma de uma imagem de Santo Antônio. Por isso, até hoje, existe a devoção da comunidade local a esse santo da igreja católica, padroeiro da cidade e nome da principal igreja local. Uma casa tipicamente usada por garimpeiros (Fig. 5A) constitui um testemunho importante dessa atividade.

Em 1860, quando a localidade ainda pertencia a Caçapava do Sul, iniciou-se uma nova fase, com forte investimento estrangeiro, que culminou na criação, pelos ingleses, da Company Mining Gold (1875), cujo engenho em ruínas (Figura 5B) constitui patrimônio cultural do município (CARVALHO, 2013). Posteriormente à emancipação política em relação a Caçapava (1882), surgiram investidores espanhóis, franceses e belgas, fundando a Compagnie de Mines d'Or du Cerrito, que possuía uma usina próxima à atual praia do Paredão (Fig. 5C), um dos principais pontos turísticos da cidade nos meses de verão. Carvalho (2013) propõe uma retomada dessa memória da mineração e do garimpo (para ela, a "alma" da cidade) através do turismo, em uma "espetacularização" de Lavras do Sul como a "terra do ouro". Para alcançar tal objetivo, com o qual este trabalho faz coro, a autora propôs uma rota pelas instalações mineiras e também por ricos imóveis urbanos, especialmente do estilo eclético, onde a fachada é o principal atrativo (CARVALHO, 2013).

Sugere-se aqui, além das medidas já propostas por Carvalho (2013) para a recuperação e uso sustentável dos engenhos relacionados às primeiras fases da mineração (talvez inclusive como centros interpretativos), com atividades culturais envolvendo a comunidade local. Pessoas que ainda disponham de lembranças (suas ou de familiares) da época do garimpo ou da mineração artesanal de ouro poderiam atuar como 'contadoras de histórias'. Ainda poderia ser idealizado uma espécie de espetáculo (teatro ou dança), preferencialmente a ser interpretado na praia do Paredão (maior afluxo de visitantes, locais ou turistas), sobre a vida e a atividade dos garimpeiros, com suas vestimentas e equipamentos tradicionais. São possibilidades que demandam a articulação entre poder público, comunidade e meio acadêmico, mas que poderiam aumentar muito a identificação das pessoas com seu lugar. 
Figura 5 - Patrimônio cultural e paisagístico relacionado à memória do garimpo e da mineração em Lavras do Sul, no território do COREDE Campanha: (A) casa do garimpeiro; (B) ruínas do engenho da Company Mining Gold; (C) barragem e praia do Paredão.
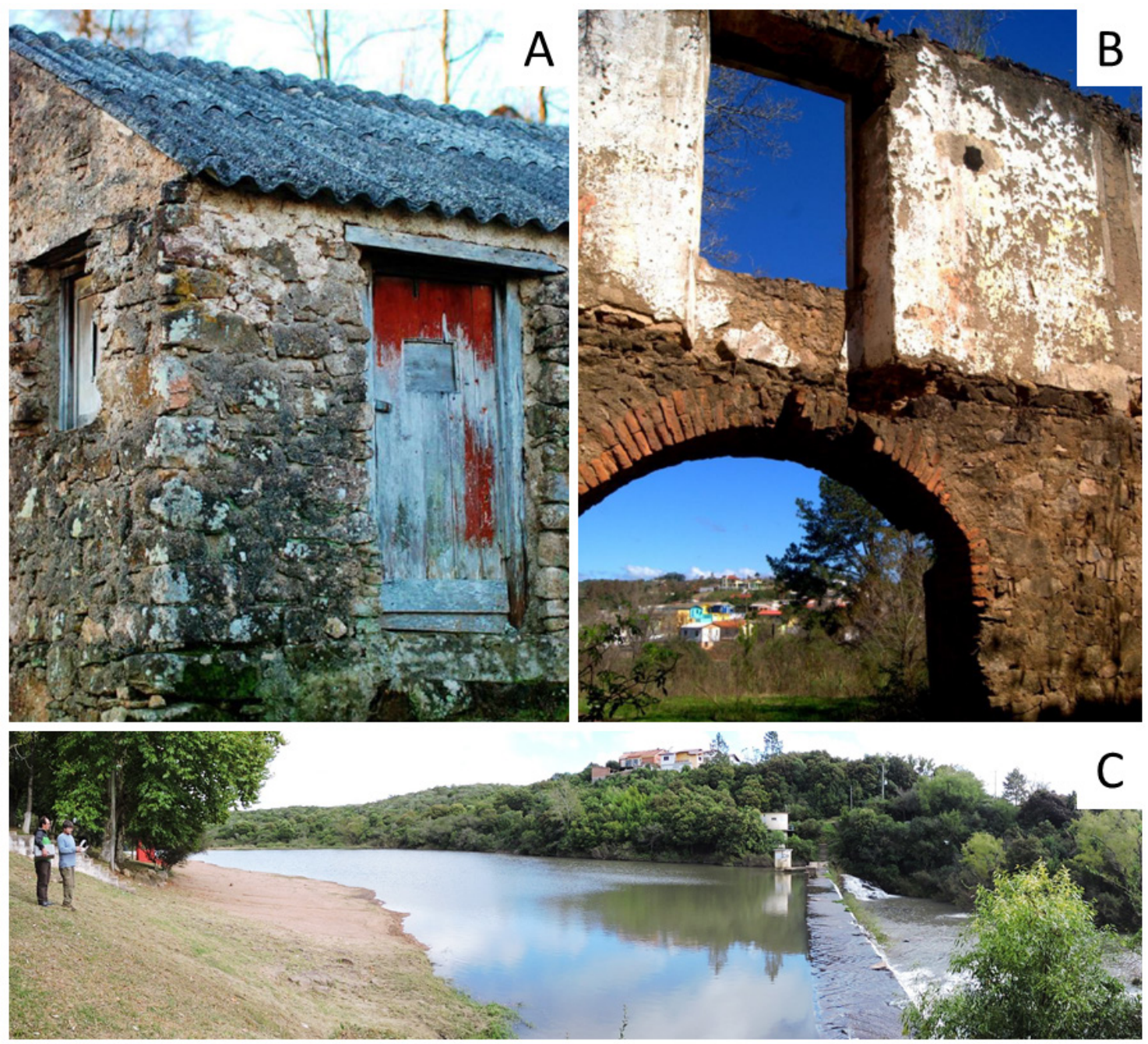

Fontes: fotos (A, B) obtidas do trabalho de Carvalho (2013); foto em (C) obtida pelos autores.

Por fim, a Vila Minas do Camaquã, em Caçapava do Sul, já no limite do território do COREDE Campanha com o COREDE Sul e com o município de Santana da Boa Vista, também tem uma origem mineira, e seu potencial em termos de geoturismo foi estudado por Domingues (2016). Essa vila é uma company-town, construída para a moradia dos trabalhadores da mineração de cobre no auge da exploração, entre as décadas de 1940 e 1970. O minério de cobre, ainda muito presente na área, sobretudo através de concentrações de malaquita (Fig. 6A), teria sido descoberto pelo proprietário das terras, Coronel João Dias, em torno de 1865. Sucederam-se diversas fases de exploração, por ingleses (até 1887), alemães (de 1888 a 1899) e belgas (de 1901 a 1908), que deixaram um importante patrimônio mineiro. Entre outras marcas, permanecem a Casa de Pedra, construída com blocos autóctones de arenitos (Fig. 6B, 6C), onde hoje funciona o Centro de Tradições Gaúchas (CTG) Ronda Crioula, e o Engenho dos Belgas (Fig. 6D), além das ruínas de uma das primeiras barragens de pedra para geração de energia do sul do país (Fig. 6CE). 
A partir de 1942, a exploração foi retomada pela Companhia Brasileira do Cobre (CBC), uma parceria entre o Governo do Estado do Rio Grande do Sul e o Grupo Pignatari. Foi então que a Vila Minas do Camaquã passou a existir, com sua arquitetura de vanguarda e serviços incomuns para o interior gaúcho na época - dispunha de hospital e cinema (o Cine Rodeio, Fig. 6F), entre outras facilidades. A vila, que chegou a ter cerca de 5.000 habitantes no auge da mineração, hoje conta com cerca de 400 moradores, e desde 2013 tenta se manter por meio dos esportes de aventura na natureza, oferecidos por uma empresa privada (DOMINGUES, 2016).

Figura 6 - Aspectos do geopatrimônio e patrimônio mineiro da Vila Minas do Camaquã, em Caçapava do Sul, no limite leste do COREDE Campanha: (A) malaquita em conglomerados da Pedra do Engenho; (B) pátio interno da Casa de Pedra, do início do século XX; (C) bloco aflorante de arenito com intraclastos lamosos, típica da unidade Bom Jardim, utilizado na construção da Casa de Pedra; (D) ruínas do Engenho dos Belgas, à frente da Pedra do

Engenho; (E) ruínas da barragem utilizada para geração de energia, construída também com blocos de rocha autóctone; (F) Cine Rodeio, construção de madeira inspirada nos saloons do velho oeste norte-americano.
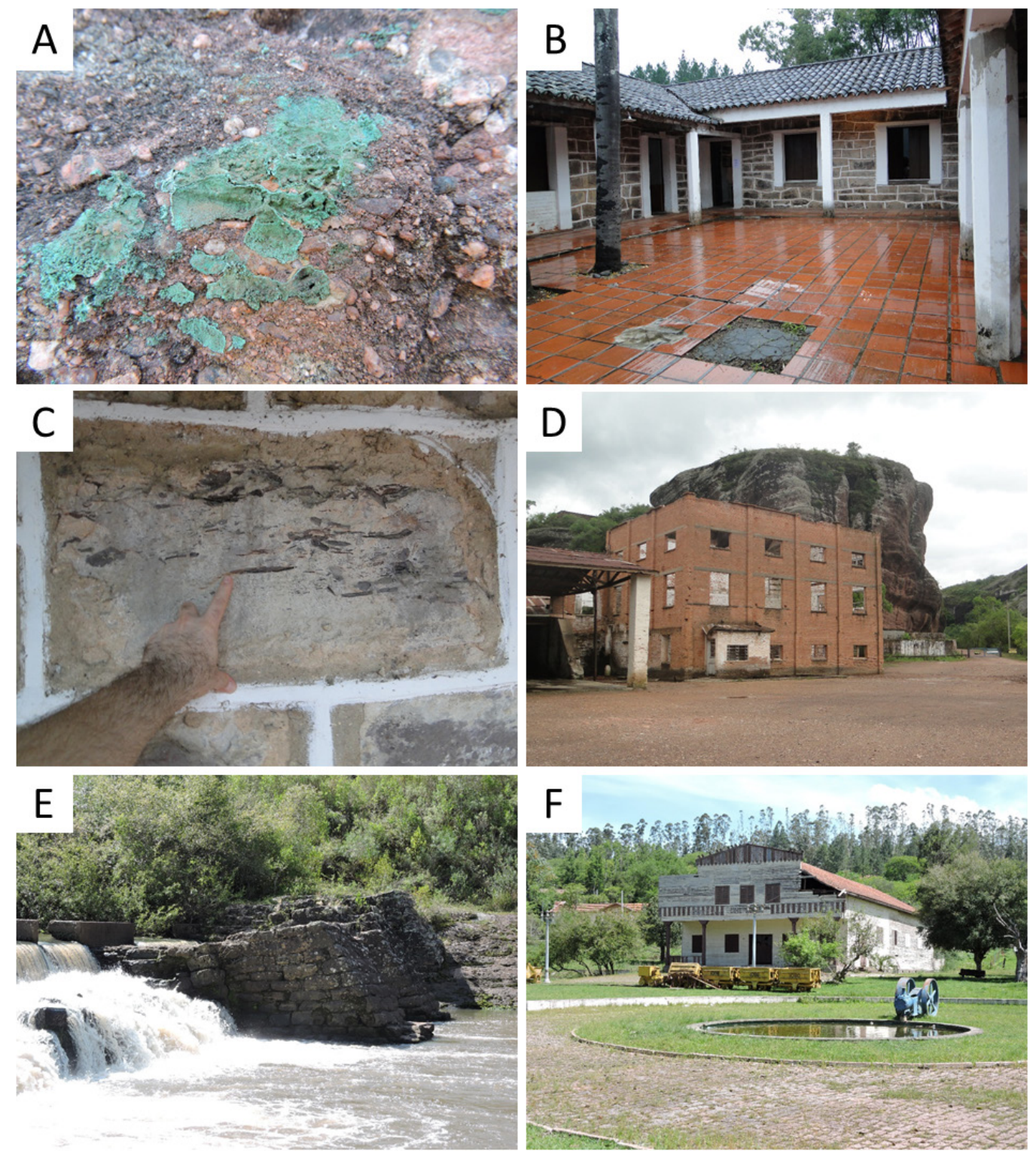

Fonte: fotos obtidas pelos autores. 


\section{CONSIDERAÇÕES FINAIS}

O COREDE Campanha possui, além de uma série de grandes áreas complexas apropriadas para o geoturismo e os esportes de aventura, elementos ex situ, contextos e identidades que complementam o panorama turístico do território. Tais conteúdos, mesmo sem substancial beleza cênica, agregam significado e ampliam o leque espacial e temporal da oferta geoturística do COREDE. Permitem o planejamento de um geoturismo que realmente promova 'viagens no tempo', experiências e sensações de um passado remoto. Ao mesmo tempo, esses contextos e identidades permitem ao visitante interagir com a história, com as transformações da paisagem, e com a própria alma da Campanha gaúcha. Os assuntos aqui abordados, evidentemente, para terem sucesso como oferta turística, precisam passar ainda por uma longa etapa de pesquisa relacionada à interpretação: idealização e produção de materiais que reconstruam ambientes, reconstituam organismos extintos, simulem paleotemperaturas extremas. Ensejam, ainda, a interdisciplinariedade, indo muito além da pesquisa geocientífica e agregando profissionais da história, das ciências sociais, da arquitetura, do turismo, da comunicação, das artes e de outras disciplinas afins com a temática da interpretação e do geoturismo.

\section{AGRADECIMENTOS}

Os autores agradecem o auxílio financeiro da Fundação de Amparo à Pesquisa do Estado do Rio Grande do Sul (Fapergs), através do projeto 16/2551-0000383-1, contemplado no Edital Fapergs Pró-COREDE Campanha. Agradecem também à população do COREDE Campanha, que elegeu o geoturismo como uma de suas prioridades de investimento na Consulta Popular de 2015.

\section{REFERÊNCIAS}

ALCALÁ-MARTÍNEZ, Luis. Territorio Dinópolis. Heritage \& Museography, v. 10, n. 3, p. 96-106, 2011.

ARAÚJO, Dina Celeste. Sobre Pareiasaurus americanus sp.nov. do Permiano Superior do Rio Grande do Sul, Brasil. I - Diagnose específica. Anais da Academia Brasileira de Ciências, v. 57. p. 63-66, 1985a.

Estudo do material sul-americano de Pareiasauroidea: II - Descrição osteológica de crânio de Pareiasaurus americanus. Anais da Academia Brasileira de Ciências, v. 57. p. 67-85, 1985b.

ARAÚJO-BARBERENA, Dina Celeste. A presença de répteis pareiassauros nos sedimentos permianos do Rio Grande do Sul. Ciência e Natura, v. 12, p. 87-91, 1990.

BORBA, André Weissheimer de. Perspectivas para a pesquisa e a atuação em geoconservação na Universidade Federal de Santa Maria (UFSM) com foco nas áreas menos desenvolvidas do Brasil meridional. Ciência e Natura, v. 36, Ed. Especial, p. 166-172, 2014.

; SELL, Jaciele Carine. Uma reflexão crítica sobre os conceitos e práticas da geoconservação. Geographia Meridionalis, v. 4, n. 1, p. 2-28, 2018.

BRILHA, José Bernardo Rodrigues. Inventory and quantitative assessment of geosites and geodiversity sites: a review. Geoheritage, v. 8, n. 2, p. 119-134, 2016. 
BUKALA, Michal; ZBOINSKA, Katarzyna; SZADKOWSKI, Mateusz. Troodos ophiolite mantle section exposed along Atalante Geo-Trail, Troodos Geopark, Cyprus. Geoscience Records, v. 3, n. 1, p. 1-6, 2016.

CARVALHO, Fernanda Ricalde Teixeira. Rota do ouro: resgate da memória da mineração em Lavras do Sul através de seu patrimônio arquitetônico urbano. Santa Maria, 2013. Dissertação (Mestrado Profissionalizante em Patrimônio Cultural), Universidade Federal de Santa Maria, UFSM.

CHÁVEZ-HOFFMEISTER, Martín F. El origen de la fauna sudamericana moderna: de Gondwana al Gran Intercambio Americano. In: PINO, M. (Ed.) El sitio Pilauco Osorno, Patagonia Noroccidental de Chile. Valdívia: Universidad Austral de Chile, 2016. p. 47-74.

CHEMALE JUNIOR, Farid. Evolução geológica do Escudo Sul-rio-grandense. In: HOLZ, M.; DE ROS, L.F. (Eds.) Geologia do Rio Grande do Sul. Porto Alegre: CIGO-UFRGS, 2000. p. 13-52.

CISNEROS, Juan Carlos; ABDALA, Fernando; MALABARBA, Maria C. Pareiasaurids from the Rio do Rasto Formation, southern Brazil: biostratigraphic implications for the Permian faunas of the Paraná Basin. Revista Brasileira de Paleontologia, v. 8, n. 1, p. 13-24, 2005.

DIAS, Eliseu Vieira; BARBERENA, Mario Costa. A Temnospondyl Amphibian from the Rio do Rasto Formation, Upper Permian of Southern Brazil. Anais da Academia Brasileira de Ciências, v. 73, n. 1, p. 135-143, 2001.

DOMINGUES, Silvio Avila. Patrimônio geo-mineiro da localidade de Minas do Camaquã (Caçapava do Sul, RS). Santa Maria, 2016. Dissertação (Mestrado em Geografia), Universidade Federal de Santa Maria, UFSM.

EVANS, Benjamin G.; CLEAL, Christopher J.; THOMAS, Barry A. Geotourism in an Industrial Setting: the South Wales Coalfield Geoheritage Network. Geoheritage, v. 10, n. 1, p. 93-107, 2018.

FERNÁNDEZ-MARTÍNEZ, Esperanza; HILARIO-ORUS, Asier; ALCALÁ, Luis et al. Actividades de divulgación del patrimonio geológico en geoparques. Enseñanza de las Ciencias de la Tierra, v. 22, n. 1, p. 61-68, 2014.

GALLO, Valéria; AVILLA, Leonardo S.; PEREIRA, Rodrigo C.L.; ABSOLON, Bruno A. Distributional patterns of herbivore megamammals during the Late Pleistocene of South America. Anais da Academia Brasileira de Ciências, v. 85, n. 2, p. 533-546, 2013.

GONÇALVES, Bruno Daniel Silva. Avaliação do valor turístico dos geossítios do Geoparque Terras de Cavaleiros. Braga, 2013. Dissertação (Mestrado em Geografia), Universidade do Minho, Portugal.

GREY, K.; CLARKE, J.D.A.; HICKMAN, A.H. The proposed Dawn Of Life geotourism trail, Marble Bar, Pilbara Craton, Western Australia - Geology and evidence for early life. Geological Survey of Western Australia, Record 2012/9, 2012.

HARTMANN, Leo Afraneo. Condições de metamorfismo no Complexo Granulítico Santa Maria Chico, RS. Revista Brasileira de Geociências, v. 21, n. 2, p. 107-113, 1991.

The Mesoproterozoic Supercontinent Atlantica in the Brazilian Shield - Review of geological and U-Pb zircon and Sm-Nd isotopic evidence. Gondwana Research, v. 5, n. 1, p. 157-163, 2002.

; REMUS, Marcus Vinicius Dorneles. Origem e evolução das rochas ultramáficas do Rio Grande do Sul desde o Arqueano até o Cambriano. In: HOLZ, M.; DE ROS, L.F. (Eds.) Geologia do Rio Grande do Sul. Porto Alegre: CIGO-UFRGS, 2000. p. 53-78.

HOLZ, Michael; CARLUCCI, Roberto. Litoestratigrafia, Estratigrafia de Sequências e Evolução Paleofisiográfica da zona de borda da Bacia do Paraná no Rio Grande do Sul durante o Eo-Permiano. In: HOLZ, M.; DE ROS, L.F. (Eds.) Geologia do Rio Grande do Sul. Porto Alegre: CIGO-UFRGS, 2000. p. 303322.

JASPER, André; GUERRA-SOMMER, Margot;MENEGAT, Rualdo et al. Afloramento Quitéria, Encruzilhada do Sul, RS: sedimentos lagunares com singular associação fitofossilífera da Formação Rio Bonito. In: WINGE, M.; SCHOBBENHAUS, C.; SOUZA, C.R.G. et al. (Eds) Sítios Geológicos e Paleontológicos do Brasil. Brasília: CPRM, 2009. v.2. 
LEE, Michael S.Y. Pareiasaur phylogeny and the origin of turtles. Zoological Journal of the Linnean Society, v. 120, p. 197-280, 1997.

MANZIG, Paulo César; WEINSCHÜTZ, Luiz Carlos. Museus \& Fósseis da região sul do Brasil: uma experiência visual com a paleontologia. Marechal Cândido Rondon: Germânica, 2012.

MATOS, Sérgio Luís Fabris de; YAMAMOTO, Jorge Kazuo; HACHIRO, Jorge; COIMBRA, Armando Márcio. Tonsteins da Formação Rio Bonito no depósito de carvão Candiota, RS. Revista Brasileira de Geociências, v. 30, n. 4, p. 679-684, 2000.

MENESES, Jorge Rui Corrêa de. Estratigrafia do Neopermiano da Bacia do Paraná no Rio Grande do Sul. In: HOLZ, M.; DE ROS, L.F. (Eds.) Geologia do Rio Grande do Sul. Porto Alegre: CIGO-UFRGS, 2000. p. 323-334.

NITA, Jerzy; MYGA-PIATEK, Urszula. Geotourist potential of post-mining regions in Poland. Bulletin of Geography - Physical Geography Series, v. 7, p. 138-156, 2014.

NOLASCO, Marjorie; PASCOAL-JUNIOR, Pedro Silvestre; TORLAY, Roger et al. Geoparque Serra do Sincorá (BA) - proposta, Anexo II. Brasília: CPRM, 2017.

OLIVEIRA, Edison Vicente; DUTRA, Tania Lindner; ZELTZER, Flora. Megaterídeos (Mammalia, Xenarthra) do Quaternário de Caçapava do Sul, Rio Grande do Sul, com considerações sobre a flora associada. Geologia Colombiana, v. 27, p. 77-86, 2002.

ORLANDI FILHO, Vitório; KREBS, Antonio Silvio Jornada; GIFFONI, Luís Edmundo. Coluna White, Serra do Rio do Rastro, SC. Sítio SIGEP 024, Sítios Geológicos e Paleobiológicos do Brasil, 2006. p. 71-86. Disponível em: http://sigep.cprm.gov.br/sitio024/sitio024_impresso.pdf Acesso em: 12 dez. 2018.

PIEKARZ, Gil; LICCARDO, Antonio. Turismo geológico na Rota dos Tropeiros, Paraná. Revista Global Tourism, v. 3, p. 1-18, 2007.

REGUERO, M. A.; GELFO, J.N.; LÓPEZ, G.M. et al. Final Gondwana breakup: the Paleogene South American native ungulates and the demise of the South America-Antarctica land connection. Global and Planetary Change, v. 123, B, p. 400-413, 2014.

RODRIGUES, J.; CARVALHO, C.N.; JACINTO, A. The concept of the geoproduct: successful examples from Naturtejo UNESCO Global Geopark. In: CONFERENCE OF EUROPEAN GEOPARKS, 14, 2017, Azores (Portugal). Abstracts Book ... p. 134. Disponível em: http://www.egnazores2017.com/uploads/ Abstracts.Book.pdf Acesso em: 10 dez. 2018.

SÜFFERT, Telmo. Carvão nos estados do Rio Grande do Sul e Santa Catarina. Informe de Recursos Minerais, CPRM, Série Oportunidades Minerais - Exame Atualizado de Projetos, n. 21, 39 p., 1997.

VARGAS-PEIXOTO, Dilson Vargas; DA-ROSA, Átila Augusto Stock; KERBER, Leonardo. Registro de Lestodon armatus Gervais, 1855 para o município de Caçapava do Sul, RS, Brasil. In: PaleoRS 2017, Rio Grande. Boletim de Resumos ... p. 98.

Data de submissão: 10/ abr./ 2019

Data de aceite: 26/ ago./ 2019 